ALCHEMY Jurnal Penelitian Kimia

Laman resmi: https://jurnal.uns.ac.id/alchemy

\title{
Karakterisasi Membran ZSM-5 yang Disintensis dengan Variasi Jenis dan Ukuran Kasa Penyangga
}

\author{
Ana Hidayati Mukaromah ${ }^{a^{*}}$, Tulus Ariyadi ${ }^{a}$, Inas Hasna Azizah ${ }^{a}$, Mifbakhuddin \\ Mifbakhuddin $^{b}$ \\ ${ }^{a}$ Prodi Analis Kesehatan, Fakultas Ilmu Keperawatan dan Kesehatan, Universitas Muhammadiyah \\ Semarang, Jl. Kedungmundu Raya 18 Semarang 50273 Telp. (024) 76740294 \\ ${ }^{b}$ Prodi Kesehatan Masyarakat, Fakultas Kesehatan Masyarakat, Universitas Muhammadiyah Semarang, Jl. \\ Kedungmundu Raya 18 Semarang 50273 Telp. (024) 76740294 \\ * Corresponding author \\ E-mail: ana_hidayati@unimus.ac.id \\ DOI: 10.20961/alchemy.16.1.25406.1-9
}

Received 19 November 2018, Accepted 27 September 2020, Published 01 March 2020

\begin{abstract}
ABSTRAK
Telah dilakukan sintesis dan karakterisasi membran ZSM-5 dengan penyangga kasa jenis 304 ukuran 200 dan 400 mesh dan jenis kasa AISI 316 ukuran 180 mesh. Tujuan penelitian ini adalah mensintesis membran ZSM-5 dengan penyangga kasa jenis 304 ukuran 200 dan 400 mesh dan jenis kasa AISI 316 ukuran 180 mesh dan mengkarakterisasi membran ZSM-5 hasil sintesis. Sintesis membran dilakukan dengan cara melapiskan prekursor ZSM-5 (coating) pada penyangga kasa yang telah diberi perlakuan dan dipanaskan pada suhu $90{ }^{\circ} \mathrm{C}$ selama 4 hari. Selanjutnya, membran yang dihasilkan dikarakterisasi engan metoda $X$-ray diffraction (XRD), scanning electron microscope-energy dispersive spectroscopy (SEM-EDS) dan Fourier-transform infrared (FTIR). Hasil citra SEM-EDS menunjukkan bahwa ukuran membran ZSM-5 yang semakin besar, menghasilkan jumlah lubang atau pori semakin banyak dengan luasan pori yang semakin kecil. Pola difraksi XRD menunjukkan bahwa membran yang dihasilkan mempunyai intensitas tertinggi pada $2 \theta=8^{\circ}$ dan $23^{\circ}$ yang merupakan karakteristik dari ZSM-5. Hasil spektra FTIR menunjukkan adanya serapan pada bilangan gelombang $450 \mathrm{~cm}^{-1}$ yang merupakan ciri khas membran ZSM-5.
\end{abstract}

Kata kunci: jenis kasa, karakterisasi, membran ZSM-5, perlakuan, ukuran kasa

\begin{abstract}
Characterization of ZSM-5 Membranes Synthesized by Variation of Support Types and Sizes. Synthesis and characterization of ZSM-5 membrane were carried out with 304 type 200 and 400 mesh gauze supports and 180 mesh AISI 316 gauze types. The purpose of this study was to synthesize ZSM-5 membrane with 304 type 200 and 400 mesh gauze support and AISI 316 type 180 mesh size 180 mesh and characterize the synthesized ZSM-5 membrane. Membrane synthesis was carried out by coating the pre-treated gauze support with the ZSM-5 precursor and was heated at $90{ }^{\circ} \mathrm{C}$ for 4 days. Furthermore, the resulting membrane was characterized by X-ray diffraction (XRD), scanning electron microscope-energy dispersive spectroscopy (SEM-EDS) dan Fourier-transform infrared (FTIR). The SEM-EDX analysis shows that the increasing of ZSM-5 membrane size allowed pores number to increase with smaller pore surface area. The X-ray Diffraction pattern (XRD) shows that the resulting membrane has the highest intensity at $2 \theta$ of $8^{\circ}$ and $23^{\circ}$ as
\end{abstract}


the characteristics of ZSM-5. The FTIR spectra results show absorption at wavenumbers $450 \mathrm{~cm}^{-1}$ which is a characteristic of ZSM-5 membranes.

Keywords: characterization, gauze type, size type, ZSM-5 membrane.

\section{PENDAHULUAN}

Zeolit merupakan mineral kristal alumina silica tetrahidrat berpori yang mempunyai struktur kerangka tiga dimensi, terbentuk dari tetrahidral antara aluminat $\left(\mathrm{AlO}_{4}{ }^{5-}\right)$ dan silikat $\left(\mathrm{SiO}_{4}{ }^{-}\right)$yang saling terhubungkan oleh atom-atom oksigen sehingga membentuk kerangka tiga dimensi, yang mengandung rongga-rongga di dalamnya terisi oleh ion-ion logam yaitu logam-logam alkali atau alkali tanah dan molekul air yang dapat bergerak bebas (Lestari, 2010). Tujuan penelitian ini adalah pertama mensintesis membran ZSM-5 dengan variasi jenis dan ukuran kasa dengan perlakuan direndam dalam larutan toluen, kemudian dalam Asam Klorida $(\mathrm{HCl})$ dan Tetra-Propil Ammonium Bromida (TPABr), kedua mengkarakterisasi membran hasil sintesis dengan X-Ray Difraction (XRD), Scanning Electron Microscopy-Energy Dispersive X-Ray (SEM-EDX) dan Fourier-transform infrared (FTIR).

Zeolite Socony Mobile-5 (ZSM-5) memiliki pori berukuran sedang dengan cincin 10 dan dua jenis saluran berbentuk lurus berukuran 5,3 $\mathrm{A} \times 5,6 \AA$ serta saluran zig-zag (berliku) 5,1 $\mathrm{\AA} \times 5,5 \AA$ A Sifat asam yang dimiliki oleh ZSM-5 menyebabkan zeolit ini sering digunakan sebagai katalis konversi gas di bidang petrolum dan petrokimia (Cejka et $a l .$, 2005). Zeolit ZSM-5 mempunyai luas permukaan yang besar dan mempunyai saluran yang dapat menyaring ion atau molekul. Zeolit dapat dimanfaatkan sebagai penyaring molekul, penukaran ion, penyaring bahan, dan katalisator (Mukaromah et al., 2017).

Tavolaro dalam Shan et al. (2004) menyatakan bahwa teknik preparasi membran zeolit meliputi perlakuan penyangga, metode sintesis in situ atau lapis demi lapis (layer by layer), metoda pembenihan, impregnasi penyangga, dan eliminasi kerusakan-kerusakan kecil. Beberapa studi melaporkan bahwa struktur fisik dan susunan kimia penyangga sangat berpengaruh terhadap pertumbuhan membran zeolit. Pemilihan penyangga sangat penting dengan mempertimbangkan konduktivitas termal, kualitas anti korosi, kekuatan mekanik dan harga. Bahan kasa stainless steel sangat dipromosikan sebagai penyangga membran mikropori, karena stainless steel merupakan logam paduan dari beberapa unsur logam, bersifat tahan korosi, kuat dan tahan terhadap reaksi oksidasi dan merupakan bahan yang ramah lingkungan (Holmbergh, 2008). Jenis atau tipe kasa stainless steel diantaranya 
304 dan AISI 316. Perbedaan kasa tipe AISI 316 dan 304 adalah kasa AISI 316 mengandung unsur Nikel lebih dari 10,5\% (Murniati, 2012). Adanya perbedaan bentuk permukaan antara bahan kasa dan zeolit ZSM-5, menyulitkan membran tumbuh sangat baik di atas permukaan kasa, maka diperlukan beberapa perlakuan terhadap kasa sebelum digunakan sebagai penyangga membran zeolit.

Hasil penelitian Utami et al. (2017) menunjukkan bahwa persentase penurunan kadar gas karbon monooksida (CO) berdasarkan variasi kasa 304-200, 304-400, dan kasa AISI 316-180 dengan direndam dalam larutan natrium hidroksida $(\mathrm{NaOH}), \mathrm{HCl}$, dan dielektrooksidasi dengan asam sulfat $\left(\mathrm{H}_{2} \mathrm{SO}_{4}\right)$ berturut-turut adalah 10,07 $\pm 0,38 \% ; 12,10 \pm$ 0,63\%; dan 15,07 $\pm 1,05 \%$. Untuk memaksimalkan kadar CO, maka kasa direndam dalam toluen selama 12 jam, kemudian dalam larutan $\mathrm{HCl}$ 15\% 20 menit dan dalam TPABr 0,1 M selama 12 jam (Kong et al., 2006).

\section{METODE PENELITIAN}

Jenis penelitian ini merupakan penelitian exksperimen. Bahan penelitian adalah kasa stainless steel jenis AISI 316-180 dan kasa 304-200, 304-400, toluen, HCl, TPABr, Ludox HS $40 \%$ b/b, Alumunium oksida $\left(\mathrm{Al}_{2} \mathrm{O}_{3}\right), \mathrm{NaOH} 50 \%$ b/v. Tahap penelitian ini adalah:

\section{Pre-Treatment pada Kasa Sebelum Digunakan Sebagai Penyangga}

Kasa stainless steel jenis 304 ukuran 200 mesh, 400 mesh dan jenis kasa stainless steel AISI 316 ukuran 180 mesh masing-masing berjumlah 4 buah dengan ukuran $3 \mathrm{~cm}$ x 3 $\mathrm{cm}$ direndam dalam larutan toluen 12 jam, kemudian dalam $\mathrm{HCl}$ 15\% 20 menit dan dalam TPABr 0,1 M selama 12 jam (Kong et al., 2006).

\section{Sintesis Membran Zeolit ZSM-5 Pada Suhu Rendah Secara Coating Pembuatan Prekursor Zeolit ZSM-5}

Sejumlah 0,1360 g natrium aluminat $\left(\mathrm{NaAlO}_{2}\right)$ dan $1,390 \mathrm{~g} \mathrm{NaOH} 50 \% \mathrm{~b} / \mathrm{v}$ ditimbang dan dimasukkan ke dalam wadah polipropilen. Sebanyak 1,5490 g TPABr dilarutkan dengan 7,3788 $\mathrm{g}$ akuades dan dimasukkan ke dalam wadah polipropilen, diaduk dengan pengaduk magnetik selama 5 menit. Setelah itu ditambahkan 24,490 g ludox HS$40 \%$, terjadi semi gel dan diaduk dengan kecepatan 900 rpm selama 6 jam.

\section{Sintesis Membran zeolit ZSM-5 pada Suhu Rendah Selama 4 Hari Secara Coating}

Prekursor zeolit ZSM-5 dilapiskan pada kasa yang sudah diberikan pre-treatment, kemudian dimasukkan dalam wadah polipropilen dengan rasio luas permukaan vs volume 
wadah 1,44 (Mukaromah et al., 2016) dan dipanaskan pada suhu $90{ }^{\circ} \mathrm{C}$ selama 4 hari. Selanjutnya membran ZSM-5 yang dihasilkan dicuci dengan akuades, dikeringkan pada suhu $60{ }^{\circ} \mathrm{C}$ semalam lalu dipanaskan pada suhu $550{ }^{\circ} \mathrm{C}$ dalam muffle furnace selama 6 jam.

\section{HASIL DAN PEMBAHASAN}

Sintesis membran zeolit ZSM-5 diawali dengan pre-treatment terhadap berbagai jenis dan ukuran kasa. Selanjutnya kasa sebelum dan sesudah pre-treatment dikarakterisasi dengan XRD (Gambar 1) dan SEM EDX (Gambar 2 dan Tabel 1).

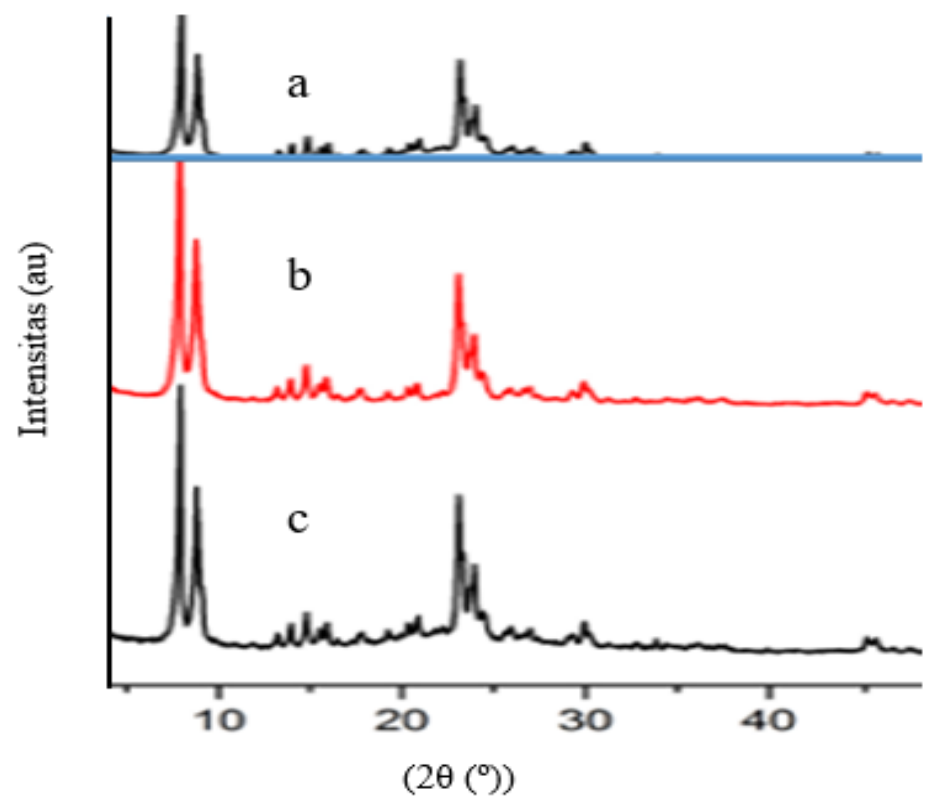

Gambar 1. Pola difraksi Sinar X Membran ZSM-5.

Gambar 1 menunjukkan pola difraksi sinar X membran yang dihasilkan disintesis dengan penyangga kasa 304-200, 304-400, dan AISI 316-180 semuanya mempunyai intensitas tertinggi pada $2 \theta=8^{\circ}$ dan $23^{\circ}$ yang merupakan ciri khas ZSM-5 (ICSD 91010) (Thommes et al., 2015). Hal ini menunjukkan bahwa membran yang dihasilkan adalah membran ZSM-5.

Gambar 2 menunjukkan citra SEM dari jenis kasa AISI 316 dan 304 dengan ukuran 180, 200, dan 400 mesh yang artinya setiap 1 inch $(2,54 \mathrm{~cm} \mathrm{x} \mathrm{2,54} \mathrm{cm)} \mathrm{berturut-turut}$ terdapat 180, 200, dan 400 lubang dengan luasan masing-masing lubang/pori berturut-turut 3,58; 3,2; dan 1,6 $\mathrm{mm}^{2}$. Dengan demikian semakin besar ukuran mesh maka jumlah lubang/pori semakin besar pula dengan luasan pori yang semakin kecil. 

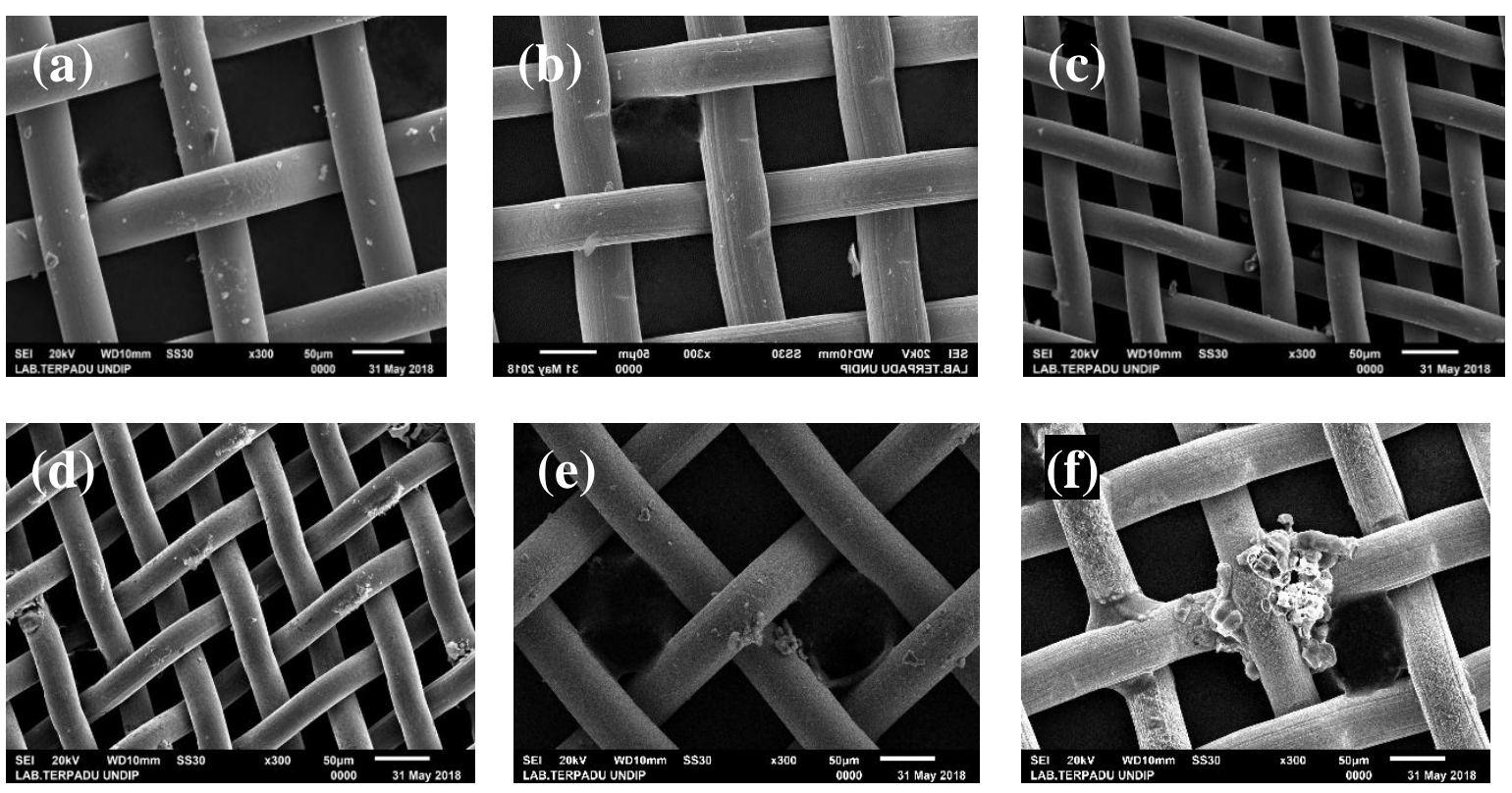

Gambar 2. SEM dari variasi ukuran kasa (mesh) sebelum pretreatment dengan pembesaran 300x (a) 180; (b) 200; (c) 400 dan setelah pretreatment dengan pembesaran 300x (d) 180; (e) 200; (f) 400 .

Tabel 1 menunjukkan komposisi EDX sebelum dan sesudah pre-treatment. Pada tabel tersebut tampak bahwa setelah pre-treatment terjadi pengurangan komponen $\mathrm{C}, \mathrm{SiO}_{2}$, $\mathrm{Al}_{2} \mathrm{O}_{3}, \mathrm{Cr}_{2} \mathrm{O}_{3}, \mathrm{FeO}$, dan $\mathrm{NiO}$ akibat reaksi dengan larutan yang digunakan untuk perlakuan perendaman. Hal ini menyebabkan permukaan kasa baik 304-200, 304-400, maupun AISI 316-180 menjadi tidak halus (kasar), sehingga diharapkan prekursor zeolit dapat menempel dengan kuat di permukaan kasa-kasa tersebut. Karakterisasi membran ZSM-5 dengan SEM-EDX dan FTIR disajikan pada Gambar 3.

Tabel 1. EDX Variasi Kasa Sebelum dan Sesudah Pretreatment

\begin{tabular}{lccc}
\hline $\begin{array}{l}\text { Jenis Kasa } \\
\text { - Ukuran Kasa } \\
\text { (mesh) }\end{array}$ & Komponen & $\begin{array}{c}\text { Komposisi (\% wt) } \\
\text { Sebelum Pre-treatment }\end{array}$ & $\begin{array}{c}\text { Komposisi (\% wt) } \\
\text { Sesudah Pre-treatment }\end{array}$ \\
\hline \multirow{3}{*}{ AISI 316-180 } & $\mathrm{Cr}$ & 16,46 & 14,05 \\
& $\mathrm{Ni}$ & 10,35 & 8,86 \\
& $\mathrm{Fe}$ & 57,56 & 48,15 \\
$304-200$ & $\mathrm{Cr}$ & 14,14 & 12,16 \\
& $\mathrm{Ni}$ & 4,95 & 4,85 \\
& $\mathrm{Fe}$ & 63,77 & 39,89 \\
\hline \multirow{3}{*}{$304-400$} & $\mathrm{Cr}$ & 12,75 & 12,69 \\
& $\mathrm{Fe}$ & 43,44 & 71,84 \\
& $\mathrm{Ni}$ & 7,79 & 7,52 \\
\hline
\end{tabular}



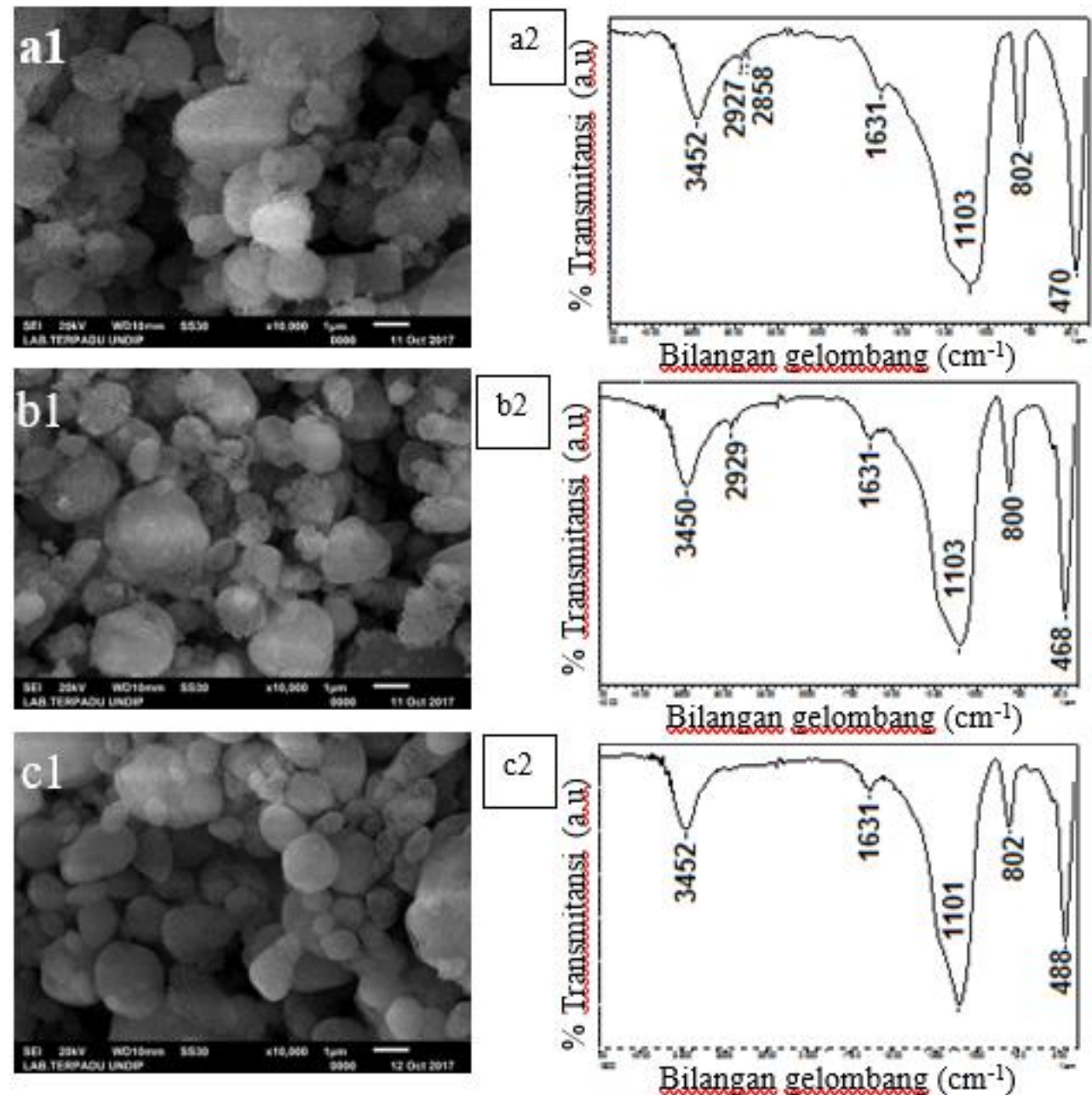

Gambar 3. Citra SEM membran ZSM-5 dengan perbesaran 10.000x dari variasi ukuran kasa (mesh) (a1) 304-200; (b1) 304-400; (c1) AISI 316-180 dan citra FTIR (a2) 304-200; (b2) 304-400; (c2) AISI 316-180 dengan pre-treatment direndam Toluen selama 12 jam, $\mathrm{HCl} 15 \%$ selama 20 menit, dan TPABr $0,1 \mathrm{M}$ selama 12 jam.

Hasil dari spektra FTIR menunjukkan bahwa membran ZSM-5 dengan penyangga kasa 304-200, 304-400, dan AISI 316-180 dengan pre-treatment direndam dengan toluen 12 jam, $\mathrm{HCl}$ 15\% 20 menit, dan TPABr 0,1 M 12 jam semuanya menghasilkan membran ZSM-5 yaitu mempunyai rasio intensitas antara bilangan gelombang $550 \mathrm{~cm}^{-1}$ dengan intensitas pada bilangan gelombang $450 \mathrm{~cm}^{-1}$ mendekati 0,81. Bila membran ZSM-5 ini akan diaplikasikan untuk penurunan kadar gas CO maka analisis minimal yang harus dilakukan adalah uji keasaman XRD.

Gambar 3 menunjukkan citra SEM dari ketiga jenis kasa semuanya menghasilkan bentuk kristal prismatik (coffin) yang merupakan ciri khas ZSM-5. Informasi yang diperoleh dari spektra FTIR dari ketiga sampel membran juga ditunjukkan dalam Gambar 3 yaitu adanya ikatan $\mathrm{Si}-\mathrm{O}$ pada panjang gelombang $1400 \mathrm{~cm}^{-1}$ sampai dengan $400 \mathrm{~cm}^{-1}$. 
Serapan pada bilangan gelombang $1100 \mathrm{~cm}^{-1}$ adalah kedudukan Asimetris T-O-T (ikatan $\mathrm{Si}-\mathrm{O}-\mathrm{Si}$ ). Serapan pada $1225 \mathrm{~cm}^{-1}$ menunjukkan vibrasi regangan asimetris $\mathrm{Si}-\mathrm{O}-\mathrm{Si}$ dan vibrasi tekuk ikatan $\mathrm{SiO}_{4}$ tetrahedral yang merupakan ciri khas dari kristal zeolite, Permukaan kasa baik 304-200, 304-400, maupun AISI 316-180 tidak halus (kasar), sehingga diharapkan prekursor zeolit dapat menempel dengan kuat. Karakterisasi membran ZSM-5 dengan SEM-EDX dan FTIR disajikan pada Gambar 3. Selanjutnya vibrasi tekuk kecil pada $962 \mathrm{~cm}^{-1}$ menujukkan vibrasi regangan dari ikatan $\mathrm{Si}-\mathrm{OH}$ (silanol), Ikatan pada $800 \mathrm{~cm}^{-1}$ mengindikasikan vibrasi regangan asimetris ikatan-ikatan $\mathrm{Si}-\mathrm{O}-\mathrm{Si}$ dan vibrasi lekuk muncul pada $450 \mathrm{~cm}^{-1}$. Serapan pada $550 \mathrm{~cm}^{-1}$ menunjukkan vibrasi regangan asimetris unit cincin pentasil ZSM-5 atau double five-membered rings ( $\mathrm{d} 5 \mathrm{r}$ ) yang merupakan karakteristik dari ZSM-5. Informasi tentang adanya kristal ZSM-5 ditunjukkan adanya serapan pada bilangan gelombang sekitar 450 sampai $500 \mathrm{~nm}$. Kristalinitas produk dapat diestimasi dengan rasio intensitas pada bilangan gelombang $550 \mathrm{~cm}^{-1}\left(\mathrm{I}_{550}\right)$ terhadap intensitas pada bilangan gelombang $450 \mathrm{~cm}^{-1}\left(\mathrm{I}_{450}\right)$. Menurut Shukla dan Pandya (1989), $\mathrm{I}_{550} / \mathrm{I}_{450}=0,81$, dianggap kristalinitaas $100 \%$. Semua serapan tersebut sesuai dengan literatur sebelumnya (Al-Oweini and El-Rassy, 2009).

\section{KESIMPULAN}

Hasil membran ZSM-5 berhasil di sintesis dari citra SEM-EDX atau morfologi membran ZSM-5 menunjukkan semakin besar ukuran mesh maka jumlah pori semakin besar dengan luasan pori yang semakin kecil. Pola difraksi sunar X (XRD) menunjukkan bahwa membran yang dihasilkan mempunyai intensitas tertinggi pada $2 \theta$ yaitu $8^{\circ}$ dan $23^{\circ}$ yang merupakan karakteristik dari ZSM-5. Hasil spektra FTIR menunjukkan adanya serapan pada bilangan gelombang $450 \mathrm{~cm}^{-1}$ yang merupakan ciri khas membran ZSM-5.

\section{UCAPAN TERIMAKASIH}

Terimakasih kepada Kemenristekdikti atas dana Hibah Penelitian Produk Terapan (2017) dan Hibah Penelitian Strategi Nasional (2018).

\section{DAFTAR PUSTAKA}

Al-Oweini, R. and El-Rassy, H., 2009. Synthesis and Characterization by FTIR Spectroscopy of Silica Aerogels Prepared Using Several Si(OR) $)_{4}$ and R"Si(OR') 
Precursors. Journal Molecular Structure 919(1), 140-145. Doi: 10.1016/j.molstruc.2008.08.025

Cejka, J. H., and Van Bekkum, H., 2005. Zeolite and Ordered Mesoporous Materials : Progress and Prospect Czech Republic. The 1st FEZA School on Zeolites, Pague Studies in Surface Science and Catalysis, volume 157. Gulf Professional Publishing, Czech Republic.

Gao, Y., Chen, M., Zhang, T., and Zhen, G. X., 2011. A Novel Method for The Growth of ZSM-5 Zeolite Membrane on The Surface Stainless Steel. Journal of Material Letter 65(17-18), 2789-2792. Doi: 10.1016/j.matlet.2011.05.110

Holmbergh, B., 2008. Stainless Steels: Their properties and suitability to welding. Avesta Polarit, Sweden.

Kong, C., Lu, J., Yang, J., and Wang, J., 2006. Preparation of Silicalite-1 Membranes on Stainless Steel Supports by a Two-Stage Varying-Temperature in Situ Synthesis. Journal of Membrane Science 285(1-2), 258-264. Doi: 10.1016/j.memsci.2006.08.027

Lestari, D. Y., 2010. Kajian Modifikasi dan Karakterisasi Zeolit Alam dari Berbagai Negara. Prosiding Seminar Nasional Kimia dan Pendidikan Kimia, 30 Oktober 2010, Yogyakarta, pp. 1-6.

Mukaromah, A. H., Kadja, G. T. M., Mukti, R. R., Pratama, I. R., Zulfikar, M. A., and Buchari, B., 2016. The Surface-to-volume Ratio of the Synthesis Reactor Vessel Governing the Low Temperature Crystallization of ZSM-5. Journal of Mathematical and Fundamental Sciences 48(3), 241-251. Doi: 10.5614\%2Fj.math.fund.sci.2016.48.3.5

Mukaromah, A. H., 2017. Sintesis Membran Zeolit ZSM-5 Secara Elektrodeposisi dan coating pada Suhu Rendah untuk Menurunkan Kadar Gas Karbon Monoksida, Disertasi Program Doktor. Institut Teknologi Bandung.

Murniati, A., Buchari, Gandasasmita, S., and Nurachman, Z., 2012. Sintesis dan Karakterisasi Polipirol pada Elektroda Kerja Kasa Baja dengan Metode Voltametri Siklik. Jurnal Sains Materi Indonesia 13(3), 210-215.

Shan, W., Zhang, Y., Yang, W., Ke, C., Gao, Z., Ye, Y., and Tang, Y., 2004. Electrophoretic Deposition of Nanosizes in Non-aqueous Medium and Its Application in Fabricating Thin Zeolites Membranes. Journal of Microporous and Mesoporous Materials 69, 35-42. Doi: 10.1016/j.micromeso.2004.01.003

Shukla, D. B., and Pandya, V. P., 1989. Estimation of Crystalline Phase in ZSM-5 Zeolites by Infrared Spectroscopy. Journal of Chemical Technology \& Biotechnology 44(2), 147-154. Doi: 10.1002/jctb.280440206

Thommes, M., Kaneko, K., Neimark, A. V., Olivier, J. P., Rodriguez-Reinoso, F., Rouquerol, J., and Sing, K. S. W., 2015. Physisorption of Gases, with Special Reference to the Evaluation of Surface Area and Pore Size Distribution (IUPAC Technical Report). Journal of Pure Applied Chemistry 87, 1051-1069. Doi: 10.1515/pac-2014-1117

Utami, R. A., Mukaromah, A. H., and Yusrin, 2017. Sintesis Membran Zeolit ZSM-5 Secara Coating Pada Suhu $90{ }^{\circ} \mathrm{C}$ Berdasarkan Variasi Jenis dan Ukuran Kasa dalam 
Menurunkan Kadar Gas CO. Prosiding Seminar Nasional \& Internasional. Oktober 2017, Universitas Muhammadiyah Semarang, Semarang, Indonesia. 